\title{
THE EFFECTIVENESS OF INTERACTIVE E-BOOKS IN THE DEVELOPMENT OF SCIENTIFIC CONCEPTS DURING "SCIENCE COURSE" AND ITS RELATION TO THE DIFFERENCE OF COGNITIVE STYLE (VERBAL/VISUAL) IN STUDENTS
}

\author{
Nader S. Shemy \\ Associate Professor, Dr., \\ Instructional Technology \\ Arab Open University, AOU, \\ Oman \\ Education Faculty, \\ Fayoum University, \\ Egypt
}

\begin{abstract}
:
The present study aims at measuring the effect of the interactive book design on the development of scientific concepts and its relation to the difference of the cognitive (verbal/ conceptual) method of science students in the ninth grade. This study is to determine the relationship between the growth of scientific concepts among students with the cognitive and verbal approach. There are differences in this growth according to the cognitive method. This study's significance is the importance of considering students' characteristics in their cognitive approaches in applying and integrating technology in education. The study results indicate that there are statistically significant differences in the development of scientific concepts among students. The differences in their cognitive methods were verbal or conceptual. The conceptual students were more developed than the verbal students. The results also indicate that the e-book has a significant impact on developing these concepts among students with a cognitive approach compared to their cognitive peers. This is because the interactive e-book did not consider the verbal students' characteristics as much as they perceived the design's visual students' characteristics. It is recommended to research the need to pay attention to the variable method of knowledge when designing interactive e-books to be more valuable to cover a larger segment of students with different cognitive methods. It is necessary to identify the cognitive techniques of students to take care of educational applications. That will help them according to their strategies to expand the recruitment of interactive electronic books in science and conduct More rigorous studies in cognitive methods and link them to modern technological innovations.
\end{abstract}

i Correspondence: email nshemy@aou.edu.om 
Keywords: interactive e-book, cognitive style (verbal/ visual), e-content, e-learning

\section{Introduction}

E-books have evolved rapidly in recent years and significantly impact, like similar technological innovations, the widespread effects on education development and industry. The e-book is a technology product that combines many technologies and is referred to in the (Lai, 2016) Store, transfer, and display a variety of information and multimedia integrated into a balanced frame of written texts, images, videos, and animations.

Interactive e-books are gaining increasing momentum because of their comprehensive coverage of many media and sources, whether audible, visual, or readable. These can include combined resources (Kitchen and Gole, 2017) and interactive books beyond merely written text compared to traditional books or Text-support electronic books.

They find that the multimedia features integrated in a way that positively affects students' ability to understand and understand, such as the presence of animation, music, sound effects, color texts for illustration, and spoken texts, giving more significant momentum in the ability to dial.

However, the cognitive methods play a crucial role in the learning process, whether by employing an interactive book or otherwise. It is considered an influence that cannot be ignored in any way in the learning process. The student uses the cognitive method that corresponds to him and his favorite. Some students prefer the verbal method in the learning process. In contrast, others prefer the conceptual approach and a cognitive style depending on many factors. The most important is how they handle the information and how it is organized. The method represents the pattern that the individual is accustomed to in how he perceives and understands the information-individuals who rely on images.

Therefore, it is necessary to understand the dimensions of students' cognitive methods when using technological innovations such as interactive writers to develop their cognitive concepts. Consequently, we will try to understand the difference between verbal cognitive and conceptual cognitive.

\section{The Study Problem}

The importance of employing and utilizing techniques in education is essential, necessary, and obligatory to lead the transformation process in the teaching and learning processes under the requirements of the 21st century, among the technological innovations. That contributes to transforming learning environments from traditional environments to more attractive environments and interactive e-books of various types (Plangsorn \& Poopan, 2017). Many studies have been interested in e-books regarding 
their impact on student achievement and motivation towards the learning process. The study's results often indicate a positive effect in raising the achievement level and student motivation. According to the book (Kennedy \& Chiasson, 2016), it is an added value to the learning process. Students find it fun to learn through their attention-grabbing advantage, which helps the teacher and a source of information facilitates and guides the learning process. It promotes students' orientation towards the learning process (Hwang, Lai, \& Wang, 2015).

There is no doubt that the positives and benefits of the e-book in its design patterns and its various types enrich the learning process and push it forward, but there is a question that can be raised in this aspect. Is it necessary to adapt interactive books based on the different cognitive methods compatible with all students? The interactive book is designed to be suitable for students with a cognitive style. That is by providing a good number of multimedia. Visual understanding and impact method on student acquisition of concepts and knowledge through an interactive book with audio, video, text, motion, and interaction will have the same effect for students with a verbal or visual cognitive style, or is it not affected by this difference? Interactive books, where they consider students' pattern, the two scenarios more than the verbal habit of students, and this cannot be proved or clarified except through scientific research testing the variable cognitive method (verbal - conceptual) to reach the result negatively or positively. How useful interactive e-books in the development of scientific concepts in the science curriculum in primary education and their relationship to students' different cognitive (verbal/visual)?

\subsection{Objectives of the Study}

This study will examine the potential impact of the difference in learning (verbal /visual) on students to develop their skills in science or not using a specific interactive e-book and measuring the extent of this effect. This research will give a broader view of the interactive book's writers in developing the design in line with the learning method's differences. According to the results of the impact based on the examination and experimentation on students with verbal patterns and students with the conceptual patterns to provide the best work of using the interactive book to improve students' learning of their different styles after development. To achieve the following:

- Determine the relationship between verbal students' scientific skills and visual students' stories with the interactive book's design.

- Analysis of the interactive book characteristics has been employed compared with the relationship between the cognitive method and the development of concepts when using the interactive book.

- Determine the interactive book's proposed development characteristics to be more compatible with the different cognitive (verbal/ conceptual) students. 


\subsection{The Importance of Studying}

Cognitive methods are an influential variable in students' academic performance, knowledge, and awareness of their importance as an independent variable that may improve designing and developing e-books by considering students' characteristics according to their cognitive methods. Among these methods is the conceptual and verbal way of thinking and the importance of cognitive methods as essential influences in the learning process

\subsection{The Limits of the Study}

This study complies with the following limits:

- This study is limited to the effect of the interactive book design on the development of scientific concepts and their relation to the cognitive (verbal/visual)

- This study was carried out in the academic year 2016-2017, the second term.

- This study was conducted in one of the Directorate General of Education schools for the Governorate of Muscat, Sultanate of Oman.

- This study was applied to 20 science students for the ninth grade.

\section{Theoretical Framework}

\subsection{First: Interactive E-book}

There is a widespread belief among many researchers that the e-book is only a traditional book, with a small difference, which is to turn it into an electronic version, but this belief is not valid. Abu Dahab and Yunus (2014) and Lai (2016) mentioned that technology had brought countless possibilities for interactive teaching, where it has been digitally developed. It is a form of learning and e-learning containing pages that have been formatted to include records of multimedia. Moreover, it is presented in several attractive ways, such as adding texts, videos, high-resolution graphics, and self-reading programs. It is a suitable alternative to paper books to disseminate information and data to the public better.

According to the study (Usta \& Güntepe, 2017), e-books are materials that can be updated easily. The content is presented in an environment where a variety of multimedia elements are easy to get. In addition to the fact that temporal and spatial boundaries do not impede content transfer to students, the content can be accessed over the Internet (Yami, 2014). The interactive e-book represents an integrated learning environment with multimedia and activities (Bozkurt \& Bozkaya, Evaluation, 2015). Interactive books allow interaction through multiple channels, such as the interaction between the user and the digital book or the book and the learning environment. They offer the ability to interact with each other. The business of the book's elements co-occurs between many of these components.

Yami also noted in her study that e-books have a set of pillars: 
- Content: Includes static or animated images, text, video clips, and illustration methods

- Program: It is responsible for reading, managing, and organizing the electronic content offered

- Device: It is responsible for running the program responsible for reading the ebook

\subsubsection{Difference between E-book and Interactive E-book}

The e-book is often more inclined to view the traditional paper-based book as it contains texts with the presentation teams through programs in supporting devices to allow this type of book to have no kind of interaction between them and the user while the e-books are the opposite It ensures interaction with the user and enhances the process of direct assessment, formative and final, and gives feedback immediately and supports the nonlinear design unlike traditional books that help the pattern of linear design only and according to the study (Muhammad and Abdullatif, 2015) that the interactive book will be from a set of pages Stereoscopic like for traditional paper books where you can flip and review those pages in a way that simulates the conventional book where these pages contain text and audio clips and pictures, drawings and videos that the student can interact with and comment and share and this gives an interactive space important task of the e-book, Her first generation emerged without interaction while the second generation was interactive as the reader shifted from a static browsing function to a participant and producer of knowledge by allowing communication and interaction with others and control the design and presentation of content.

\subsubsection{Advantages and Disadvantages of Interactive E-book}

The interactive e-book has advantages and disadvantages that can be summarized according to the (Ebied \& Rahman, 2015) study as follows:

- Online interactive books can be accessed easily after being uploaded.

- Availability of time and money on the update side, as updating it is easy and straightforward compared to traditional books' modernization.

- It can handle many multimedia as opposed to conventional e-books that are limited to text and still images.

- The search process within the e-book is facilitated by the availability features that allow searching itself or through hyperlinks from other sources such as the Internet.

- Give students more flexibility in allocating colors, backgrounds, and characteristics suitable for individuals with special needs.

- It is environmentally friendly by providing large quantities of printed paper, which is a great added value given the worsening environmental problems that the world suffers from over-consumption of resources. 
- Give greater satisfaction to the reality of the new technologies that students are using, such as smart devices; thus, providing these interactive books will also give added value to those devices that have become a reality that cannot be ignored.

At the same time, the same study considers that the interactive e-book also has many disadvantages that should be addressed:

- The lack of supporting devices that allow reading the content of these books, but this point is quickly exceeded at present to provide many free applications and software that work in most types of devices. The same devices are now supporting the reading of the content of e-books of ordinary and interactive types.

- Lack of equipment for each student at the school but with an excellent interactive book design enables students to actively use interactive e-book or use the inverted classroom strategy to use e-books outside the school and discuss content during classes.

- Lack of support networks in schools, where most interactive e-books to be employed optimally and utilize their potential. In the form required, the devices should be connected to the Internet. We see that this challenge will be overcome with the proliferation of supporting networks and broadband lines in educational institutions such as schools or homes on both.

- Disadvantages are also the fragmentation of some student groups, which may be due to their learning patterns and cognitive styles. The study (Zsofia K, Elise K, \& Adriana G, 2015) suggests that interactive e-books may distract attention. Some students and other types of non-interactive e-books may be better for them and less harmful.

\subsubsection{The Design Criteria of Interactive E-book}

Many studies indicate that specific design and technical design standards must be adhered to when designing an electronic book, whether traditional or interactive, as the design directly impacts the user experience when interacting with the book. Therefore, there is a need for standards (Nielsen \& Budiu, 2012) found that it is necessary to design, produce, and evaluate user interface screens' effectiveness from instructional design principles. The most important of design criteria for e-books which is to be used in practice and classified as a study (Abu Dahab and Younis, 2013);

- Technical criteria: It relates to ease of handling and use of users. The appropriate design and quality of the sounds and graphics selected and video clips are clear and determined.

- Educational standards: It includes criteria related to the review of educational goals, research tools, guidance and guidance, and methods of stimulating and motivating learners.

The study of (Al-Hussein and Al-Ghamdi, 2015) summarizes these educational standards as follows: 
- Learners' characteristics: interactive e-books should consider students' attributes of the target phase, consider individual differences, and enhance enrichment information while providing remedial plans for students who may fail in certain parts.

- Learning Objectives: The teaching objectives should be carefully and clearly defined and measurable and aim to develop students' scientific thinking abilities.

- Content of learning: The content should be consistent and appropriate to the student's skills and experiences and includes the course topics. Moreover, the contents should be directly linked to the goals and support the content's proper media. It should contain the elements of attraction and suspense and the formulation of explicit and include various activities, including the difficulty and linking of content enriched materials and facilities. The student should move between parts and should be reviewed to ensure his scientific and linguistic health.

- Educational activities: Activities should vary to include aspects of cognitive, emotional, and skill content and be of a variety of styles to have activities of a pedagogical, objective, practical and practical nature to motivate students towards the learning process and to take into consideration individual differences among students.

- Feedback: It is of great importance that interactive e-books should consider that feedback is immediate and varied, such as written or phonetic, as appropriate to the age group of learners.

According to (Alshaya \& Oyaid, 2017), the technical criteria for designing an interactive eBook are:

- The screens' design: The main screen should contain a welcome to the student with the strengthening tools and the assistance distribution of the elements in a balanced so as not to overwhelm the written texts on the drawings and preferably the graphics more than textbooks.

- Written texts: Fonts should be prominent, legible, familiar, uncoordinated, and non-plural in using multiple patterns of lines not to exceed three ways in the upper limit.

- Images: The animation may be an attraction, but its use without rationalization may distract attention. The use of static or moving images should be balanced, and a specific target should be set when choosing a fixed or moving image display that has added value to the learning process.

- Colors: The design should avoid the rich colors of the eye. The sun and the use of colors familiar with some colors to draw attention and focus on essential points, and many colors do not prefer to use more than three colors maximum.

- Video: The videos included in the book should match the student's age range, appropriate and directly related to the goals, provide a control bar for the student to return, and the video is suitable for the display. 
- Sound: The tracks should be selected carefully and carefully and be of high quality and without interference and directly related to the content for easy understanding.

- Interfaces: A home screen containing the addresses can be controlled through the transition of content by linking those titles of content pages with the design of attractive buttons appropriate and compatible with the book's overall strategy. And prefer to distinguish links in thicker font and a different color suitable with proper explanations for the student to facilitate the process and browse the required content.

\subsection{Second: Cognitive Styles}

The interest in cognitive methods led to the emergence of definitions from the 1960s to the present. Shami (2013) stated that Harvey Harvey, in 1962, knew early cognitive processes as the method that filters information that comes to the individual from the environment. "Kagan Cagan" was known in 1967 as a term that refers to the type of consistent performance method, which individuals prefer in organizing their perception and conceptualization of the environment. "Messick" in 1976 defined cognitive techniques as patterns consistent with each other to equip and manage. The information is mentioned (Real, 2004) that it is one of the essential factors that illustrate the differences in individuals' quality or quantity. Also, they showed the individual differences in the processing of information by trying to make decisions or solve problems or clarify those stimuli and respond to them.

Al-Maaadi (2011) states that individuals receive information, experiences and then process and store them according to their preferences, which may be descriptive or negative. Individuals receive information through the senses such as hearing or sight and are transmitted through the brain's nerves and treated. They differ in the methods they prefer. One may be described as a phonetic person and another as my perception; this dramatically distinguishes individuals' abilities. Verbalisms have the knowledge and skill to employ and use words and save them faster. Save them and then call them when needed.

In her study (Al-Tai, 2017) also notes that Snow and All, 1980, know cognitive methods as students' methods of conservation, citation, and retrieval, and give an idea of the process of learning, the materials they want to study, and the ways they use. The method of organizing, storing, retrieving, and generating information the study (Prayekti, 2018) states that individuals have different characteristics and thus differ in their level of intelligence and ability to solve problems. The ability to think varies mainly in obtaining information, storing it, and applying the knowledge they acquired.

We have already seen that cognitive methods indicate a difference in organizing information in individuals and how to equip it; this undoubtedly significantly affects the strategies and plans most successful in learning to correspond with the techniques cognitive of students. 


\subsection{Cognitive Style (Verbal / Visual)}

The concept is based on the form of two-way coding. This model assumes two sites for storage and representation of ideas, one based on image formation and the other on the composition of words (Paivio, 2006). As mentioned (The Trick, 2014), the verbal method is that individuals deal with information through listening, often speaking out loud, and socializing, preferring games that deal with words as crossword words. Figurative individuals (Zayyat, 2001) say that visual individuals choose to store information. They have a clear tendency to use diagrams and illustrations to interpret and solve the problems they face, as they need clear mental images to understand new information. They do not prefer to work collectively and socially in a less verbal manner. They deal more easily with the pictures, drawings, and information presented in the-data format.

The characteristics of verbal and symbolic individuals can be illustrated as summarized by (Al-Ta'I, 2017) in their study that verbal individuals:

- Depend on words primarily,

- Socialists tend to social relations more,

- They prefer discussions and listen to a solution to address information.

- Enjoy solving more verbal problems.

- Tend to learn partial macro allowance.

- They have a more remarkable ability to analyze situations and understand facts.

- Prefer reading.

- More active and lively.

And she stated that visual individuals:

- Depend on the photos.

- They have a more remarkable ability to visualize the face, features, and places;

- Use imaginations to remember.

- Tend to process information through drawings, images, and charts.

- Non-social.

- Have a better ability to understand new and unspecified facts.

- Care about generalities and the details.

\subsection{Previous Studies}

Several studies have examined the impact of the interactive e-book, and other studies of the cognitive-style variable have been investigated. A number of these studies will be reviewed here:

The study found that participants in the survey used interactive e-books as a resource for educational resources. The study confirmed that interactive e-book design helped students study interactive books in secondary school students (Pabrua Batoon, Glassman Morales, \& Yanez Figueroa, 2018). Develop necessary learning skills such as the ability to employ technology and literacy skills and academic achievement. The study attributed this to the positive impact of the book's contents, interactive audio, and visual high, and emphasizes the study (Alshaya \& Oyaid, 2017), which examined the 
importance of the use of e-. This study's results indicate that the students had the necessary skills to download and read e-books and benefit from their characteristics. The study of (Wang \& Huang, 2015) examined the effect of the age group. The results showed that there was an essential interaction between the three variables. It was found that the younger students found that the mechanism of having specific paragraphs and controls was useful for them.

In comparison, this did not affect the older students, indicating that the age group is a factor in changing characteristics and should be considered. The development of the cognitive and psychological design of the e-book audio, as confirms the study (Kitchen and Gul, 2017) to a strong relationship between the superiority of students in Scientific research and reading and their use of e-books sources for ease of availability and cheap cost compared to traditional books. The study of the role of e-books in the study of students at the University of Al-Sultan Qaboos (Al-Hafeedh, Lane-Kelso) that the students with their multiple and varied experiences (Mohamed and Abdullatif, 2015). The development of visual and auditory perception using e-book for students with special needs found that the e-book contributed to increasing students' collection in the experimental group. The study confirmed that the interactive book contributed to the development of scientific concepts among students in the levels of memory, understanding, application, and analysis. It also contributed to the development of skills.

The study of Al-Taei (2017) which studies the relationship between vocal style and communicative competence, suggests that humanities students are more verbal than others. In contrast, applied science students tend to be more visual, and females are more verbal than males. The study (Kibar \& Akkoyunlu, 2016) showed that the cognitive style was more robust among science students while the vocal tendencies were strong among the students' literary fields. The study (Hariri, Asadi, \& Mansourian, 2015) found a relationship between behaviors On the Internet and users' cognitive methods. The conceptual individuals were more wrong to formulate the appropriate search words. The verbal tend to search narrowly and then expand their field of research gradually. Simultaneously, the researchers' tendency to explore badly as verbalists takes longer than the visionaries in completing the tasks required of them, indicating that the verbalcognitive method affects the effectiveness of users' behavior on the Internet.

In analyzing the results of these studies, we find that many studies confirm the interactive e-book in raising students' level of achievement and increase students' motivation and motivation and the relationship of cognitive methods of achievement levels and motivation and preferences of learning. However, there is a lack of research and studies that try to establish connections between cognitive strategies and e-book Interactive, which requires researchers to consider interactive e-books. The consideration from other angles enriches the research side, reflecting positively in the issues' deepening relationship. $\mathrm{Tu}$ We believe that cognitive methods as a variable in studies dealing with education technology are essential and vital because of the negative and positive effects of using technology in the teaching and learning processes. 


\section{Research Procedures}

\subsection{Research Methodology}

This study was followed by a semi-empirical approach to experimental hypotheses (AlKhalili, 2012) to study the effect of interactive e-book design on developing scientific concepts based on the difference of cognitive style (verbal/visual) in 9th-grade students. We expect that this methodology will contribute to integrating integrated interpretations and an interpretation of the underlying relationships.

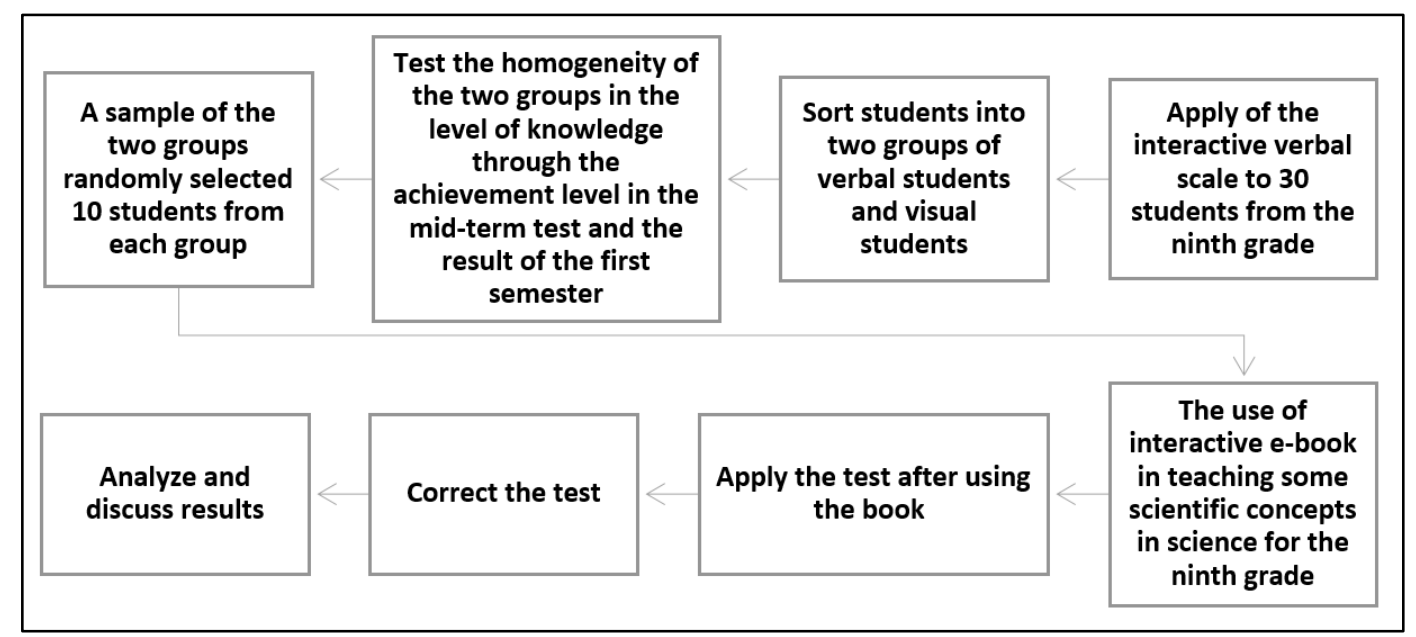

Figure 1: Semi-experimental design diagram

\subsection{Study Tools}

The following study tools are designed as:

- Scale (verbal /visual): The scale (Altai, 2017) was adopted due to the following reasons:

1) The scale was judged, and it is clear paragraphs.

2) The scale is modern and applied in 2017.

3) Very suitable for the study sample after clarifying and modifying some of the words to be more understanding and significant for the students of this stage for more accurate results in students' classification.

- Post-test: It is used to measure the growth of students' scientific concepts after the experimental treatment of the two groups to employ an interactive e-book in the teaching of one of the units of science for the ninth grade.

There are 17 items prepared to measure the growth of the students' scientific concepts in the levels of understanding, memory, application, and higher abilities. In the space unit for the lessons contained in the interactive e-book, the test vocabulary is of multiplechoice type for easy debugging, and it covers many concepts. Also, it reduces guesswork and mitigates self-corrected. 


\subsection{Procedures to Determine the Study Sample}

The study sample was selected according to the following procedures:

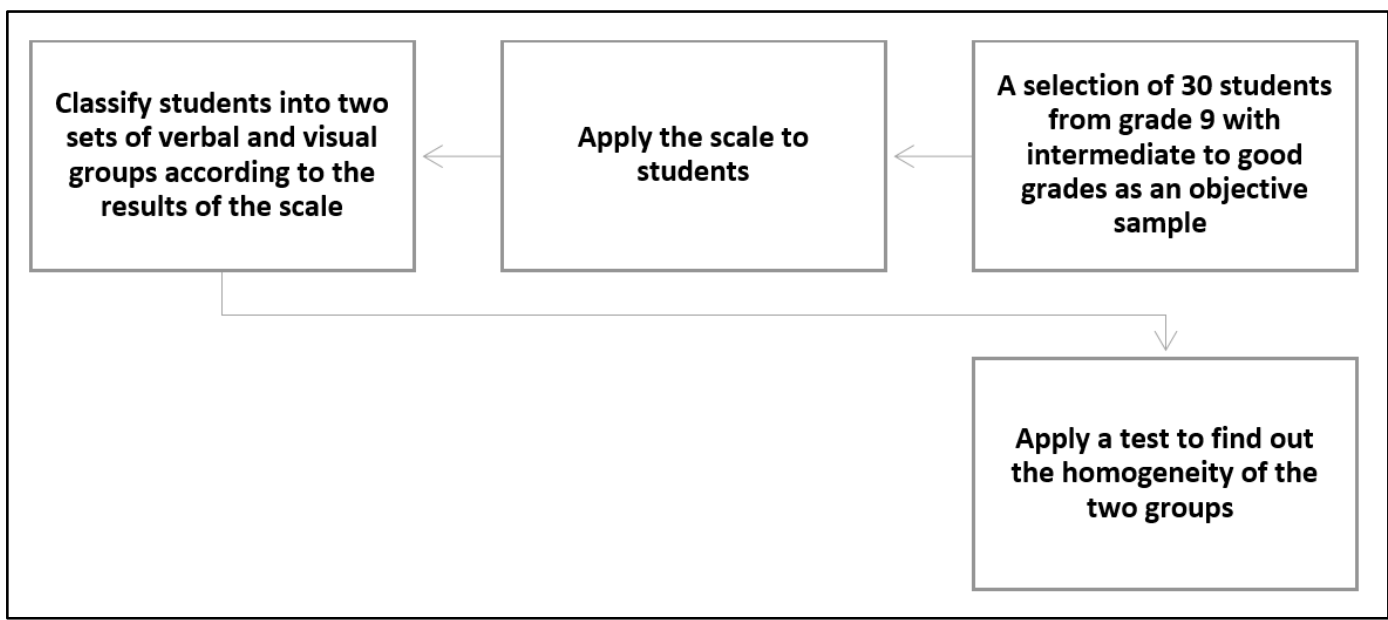

Figure 2: Sample selecting diagram

The two groups' homogeneity was verified by a short test of 10 vocabulary types of multiple-choice questions. The results of the trial were analyzed through the SPSS program.

Table 1: The homogeneity of the two groups

\begin{tabular}{|l|c|c|c|c|c|c|}
\hline Group & (do) & Average & Standard deviation & (T) & (Sig 2-tailed) & Significance \\
\hline Visual & \multirow{2}{*}{18} & 12.300 & 1.337 & \multirow{2}{*}{0.174} & 0.864 & \multirow{2}{*}{ None } \\
\cline { 1 - 6 } Verbal & & 12.300 & 1.229 & & \\
\hline
\end{tabular}

The table shows no statistically significant differences at the level of statistical significance $(\alpha=0.05)$. This confirms the homogeneity of the two groups. Therefore, experimental procedures can be applied to both groups.

\subsection{Study Variables}

\subsubsection{Independent Variables}

1. Cognitive approach:

- Students with a verbal cognitive approach,

- Students with a visual cognitive approach.

2. Interactive e-Book.

\subsubsection{Dependent variables}

- Development of scientific concepts

\subsection{Study results and interpretation}

The first hypothesis of the research indicates that there are no statistically significant differences at the level of $\alpha$ (00.05) for the design of interactive e-book in the development 
of scientific skills of students with the verbal and visual style of students. After applying the interactive e-book and the post-test, the results of the students were analyzed in the test through the SPSS program:

Table 2: Results of the students were analyzed in the pre and post-test

\begin{tabular}{|c|c|c|c|c|c|c|c|}
\hline Vocabulary & Group & Average & $\begin{array}{l}\text { Standard } \\
\text { deviation }\end{array}$ & (T) & (df) & $\begin{array}{l}\text { (Sig 2- } \\
\text { tailed) }\end{array}$ & Significance \\
\hline \multirow{2}{*}{ Memory } & Visual & 8.400 & 0.843 & \multirow{2}{*}{2.741} & \multirow{2}{*}{18} & \multirow{2}{*}{$0.017^{*}$} & \multirow{2}{*}{$\begin{array}{l}\text { There is an } \\
\text { indication }\end{array}$} \\
\hline & Verbal & 6.600 & 1.897 & & & & \\
\hline \multirow{2}{*}{ Understanding } & Visual & 7.200 & 2.149 & \multirow{2}{*}{3.239} & \multirow{2}{*}{18} & \multirow{2}{*}{$0.005^{*}$} & \multirow{2}{*}{$\begin{array}{l}\text { There is an } \\
\text { indication }\end{array}$} \\
\hline & Verbal & 4.600 & 1.349 & & & & \\
\hline \multirow{2}{*}{ Application } & Visual & 5.600 & 1.264 & \multirow{2}{*}{0.709} & \multirow{2}{*}{18} & \multirow{2}{*}{0.490} & \multirow{2}{*}{$\begin{array}{l}\text { There is no } \\
\text { indication }\end{array}$} \\
\hline & Verbal & 5.000 & 2.357 & & & & \\
\hline \multirow{2}{*}{ High abilities } & Visual & 4.800 & 1.398 & \multirow{2}{*}{1.411} & \multirow{2}{*}{18} & \multirow{2}{*}{0.175} & \multirow{2}{*}{$\begin{array}{l}\text { There is no } \\
\text { indication }\end{array}$} \\
\hline & Verbal & 3.800 & 1.751 & & & & \\
\hline \multirow{2}{*}{ Total } & Visual & 26.000 & 1.885 & \multirow{2}{*}{6.364} & \multirow{2}{*}{18} & \multirow{2}{*}{$0.00^{*}$} & \multirow{2}{*}{$\begin{array}{l}\text { There is an } \\
\text { indication }\end{array}$} \\
\hline & Verbal & 20.000 & 2.309 & & & & \\
\hline
\end{tabular}

In the table, we notice statistically significant differences at the level of $(\alpha 0.050 .05)$ at the concepts' level. This difference leads to the rejection of the alternative theory's hypothesis and acceptance with statistically significant differences. The story of significance is 0.017 for the group of students with visual cognitive style (8.400). Given the interactive e-book design and the presentation of the scientific concepts, it came through a multimedia set, such as video, which touched the stellar circle concept.; on the sun's mages and centrality to universe and centrality of the Earth to the universe. Thus, the interactive book's design with various forms of illustration, images, and video helped understand these concepts more by students of the abstract style than verbal students. The Felder \& Silverman model for the classification of bipolar cognitive methods, as reported in the Samia \& Amirat (2017) study, indicated that students with a cognitive approach to this model tend to absorb knowledge through static and dynamic images. The video clips and illustrations, shapes, maps, and charts, while students with cognitive and verbal methods tend to absorb knowledge through interpretations, whether oral or written.

This is also applicable at the level of understanding, where there are statistically significant differences at the level of $\alpha 0.050 .05$. The story of knowledge of these scientific concepts for students' benefit with the visual cognitive style, where the arithmetic mean is (7.200); there are statistically significant differences at the function level $(\alpha 00.05)$ for application-level of concepts and higher abilities level. This difference can be explained by the availability of practical activities accompanying the interactive e-book. The students worked in this aspect in exploring the practical application of the concept of retrogressive movement. Practical application positively affected the lack of differentiation of students in the two groups, the performance of students, verbal and visual students were soon at the level of application and higher abilities. The total number of tests was statistically significant at the level of $\alpha(0.050 .05)$ for students with visual 
cognitive style in terms of the general level. (26.00); this indicates that scientific concepts' growth was better for students of visualizations about verbal students when employing the e-book. Therefore, we conclude a statistically significant relationship at the significance level ( $\alpha$ 00.05) for designing the interactive e-book in developing scientific skills Parents with visual and verbal cognitive style.

The second hypothesis of the research indicates the absence of an impact of the interactive e-book design in developing scientific skills among students with a visual and verbal cognitive style.

Table 3: Results of the second hypothesis verification

\begin{tabular}{|l|c|c|c|c|c|c|}
\hline Group & $\begin{array}{c}\text { The overall } \\
\text { mark }\end{array}$ & Average & $\begin{array}{c}\text { Standard } \\
\text { deviation }\end{array}$ & $\mathbf{( T )}$ & $\begin{array}{c}\text { (Sig 2- } \\
\text { tailed) }\end{array}$ & Significance \\
\cline { 1 - 6 } Visual & \multirow{2}{*}{34} & 26.000 & 1.885 & \multirow{2}{*}{6.364} & $0.00^{*}$ & $\begin{array}{c}\text { There is an } \\
\text { indication }\end{array}$ \\
\cline { 1 - 6 } & Verbal & 20.000 & 2.309 & &
\end{tabular}

Hence, we conclude that there is an impact of the interactive e-book design in developing students' scientific skills with a visual and verbal cognitive style. The interactive e-book contributes to the development of concepts even more to the graphic students than to the verbal students. By returning to students' characteristics with the verbal cognitive technique mentioned (al-Tai, 2017), their reliance on learning more about images indicates that the interactive e-book was more. The dependence on learning more about ideas may also be interpreted as an agreement with the study (Kibar \& Akkoyunlu, 2016), which stated that verbal persons are more inclined to literary material than scientific because of their cognitive characteristics. However, this is possible. We also find that interactive e-book capability in terms of appropriate design for students with the cognitive, verbal method is critical. In its benefit and achieve more excellent added value through aggressive recruitment in the study of science or other materials.

\section{Conclusions}

According to the results, this study reached the following results:

- The design of interactive e-book is a crucial factor in developing students' scientific concepts according to their cognitive methods.

- Students with a visual cognitive style benefit more from interactive electronic books based on images, texts, maps, illustrations, and video clips and contribute to these books supporting the growth of knowledge concepts.

- Students with a verbal cognitive style benefit less from e-books that do not consider their characteristics. They rely more on words and reading texts than on images and forms in the learning process. 


\title{
5.1 Suggestions
}

Conduct a similar study to examine the impact of cognitive (verbal-visual) after the electronic book development to be more considerate characteristics of students' verbal.

Studies to examine the cognitive (verbal-visual) impact on other variables such as intelligence and critical thinking and motivation.

Studies to examine the impact of other cognitive methods, such as the cognitive method (Contemplative / Impulsive), in developing scientific concepts or motivation or critical thinking when employing the interactive e-book.

\section{Conflicts of Interest}

The author declares no conflicts of interest.

\begin{abstract}
About the Author
Dr. Nader S. Shemy is an associate professor in instructional technology and online learning. He is working as the head of the education program in AOU, Oman. Previously, the head of the instructional technology department in the faculty of education, Fayoum University, Egypt. And the supervisor in the National e-Learning Center (2008: 2013) NELC, Egypt. He is doing lots of activities in the e-learning field with other entities like the school of education in Edinburgh University, UK, The National Center for e-learning and distance learning, KSA, Ministry of Communications, Sudan, Education reform Program (ERP) USA, Education Support Program (ESP) the USA, the Egyptian eLearning University, Egyptian Police Academy, and Egyptian Public Universities (EPU).
\end{abstract}

\section{References}

Abu Dahab, Mahmoud Mohammed, Yunus, Sayed Shaaban (2013). Effectiveness of different styles of interactive e-book design in developing skills of designing and producing electronic courses for computer teachers. Arab Studies in Education and Psychology, 41 (1), 145-200.

Ahmed Mohammed Ali (2015). The suggested e-book for the secondary grade biology course is based on student achievement in the state of South Darfur. Journal of the Generation of Human and Social Sciences, 13 (1), 27-56.

Hussein, Mohammed Osman, and Al-Ghamdi, Mohammed Rizk (2015). Standards of ebook design to support the educational process at the primary level. Saudi Journal of Educational Technology Research, 1 (1), 20-24.

Mohamed Mahmoud (2014). The trick, Teaching Teaching Skills, i. Amman: Dar Al Masirah for Publishing, Distribution and Printing.

Khalili, Khalil Youssef (2012). The basics of educational scientific research. Dubai: Dar Al Qalam. 
Al-Dahdouh, Asmaa Sulaiman (2010). Cognitive methods and their relation to psychological stress among Palestinian university students. Gaza, Palestine: Islamic University: Unpublished Master Thesis.

Aldrider, Abdel Moneim Ahmed (2006). Barometric and Labarometric Statistics in Psychological, Educational and Social Research Tests, I. Cairo: The World of Books.

Radi Al-Waqfy (2004). Educational Psychology: Introduction to Psychology. Amman: Dar Al Shorouk for Publishing and Distribution.

Sahar, Hisham Ibrahim (2015). The impact of the use of the two types of games and role plays in the development of scientific concepts in the science of third grade students. Gaza, Palestine: Islamic University: Unpublished Master Thesis.

Salim, Mary (2009). Cognitive Psychology, i. Beirut: Arab Renaissance House.

Shami, Jamal al-Din (2013). Cognitive methods of defining human personality. Riyadh: King Abdulaziz University.

Tae, Saleh's Hands (2017). Communication efficiency and its relation to the (verbal conceptual) method of university students. Diwaniyah, Iraq: University of Qadisiyah, Faculty of Education: Master's thesis unpublished.

Abdali, Ali Kazem (2017). Cognitive learning methods. Baghdad: University of Mustansiriya.

Abssi, Zakaria Fuad, Lulu, Fathia Sobhi, and Abu Shuqair, Salem (2016). The impact of employing an interactive book in the development of concepts and thinking skills above the knowledge of science in the students of the seventh grade. Gaza, Palestine: Islamic University: Unpublished Master Thesis.

Ezzat, Farid Mohamed (2013). The e-book's name, its evolution, its advantages and its disadvantages. Journal of Education, 41, (178) .271-314.

Mohammed, Adel Abdullah and Abdul Latif, Ashraf Ahmed (2015). The effectiveness of the use of e-book in the development of visual and hearing perception among first grade students with learning disabilities. Journal of Special Education, 17 (1), 91148.

Kitchen, Fairouz, Ghoul, Najoud (2017). The impact of e-books on the acquisition of reading and knowledge collection among students of the University of Tebessa. Tebessa, Algeria: Al-Arabi University of Tunis: Unpublished Master Thesis.

Maahedi, Maysa Ahmed (2011). NLP and its relationship to the integration of cognitive patterns. Amman: Dar Al Safa Publishing.

The Ministry of Education (2014). Space exploration. Author of Science Book, 9th Grade, Second Semester (pp. 64-66). Muscat: Ministry of Education.

Yami, Hoda Nasser (2014). The effectiveness of an interactive eBook to develop the skills of designing and employing web quests for female students. Makkah, Saudi Arabia: Umm Al-Qura University: Unpublished doctoral thesis. 
Alshaya, H., \& Oyaid, A. (2017). Designing and Publication of Interactive E-Book for Students of Princess Nourah Bint Abdulrahman University: An Empirical Study. Journal of Education and Practice , 8(8),41-57.

Bozkurt, A., \& Bozkaya, M. (2015). Evaluation Criteria for Interactive E-Books for Open and Distance Learning. International Review of Research in Open and Distributed Learning, 16(5),58-82.

Bozkurt, A., \& Bozkaya, M. (2015). Evaluation Criteria for Interactive E-Books for Open and Distance Learning. International Review of Research in Open and Distributed Learning, 16(5),58-82.

Ebied, M. M., \& Rahman, S. A. (2015). The Effect of Interactive e-Book on Students' Achievement at Najran University in Computer in Education Course. Journal of Education and Practice, 6(19),71-82.

Hariri, N., Asadi, M., \& Mansourian, Y. (2015). The impact of users' verbal/imagery cognitive styles on their Web search behavior. Aslib Journal of Information Management, 66(4),401-423.

Hwang, G.-J., Lai, C.-L., \& Wang, S.-Y. (2015). Seamless flipped learning: a mobile technology-enhanced flipped classroom with effective learning strategies. Journal of Computers in Education, 2(4),449-473.

Kennedy, L., \& Chiasson, S. (2016). Teaching with an Interactive E-book to Improve Children's Online Privacy Knowledge. The 15th International Conference on Interaction Design and Children (pp. 506-511). Manchester: Association for Computing Machinery.

Kibar, P., \& Akkoyunlu, B. (2016). University Students' Visual Cognitive Styles with respect to Majors and Years. Eurasia Journal of Mathematics, Science E Technology Education, 12(2),321-333.

Korat, O., Kozlov-Peretz, O., \& Segal-Drori, O. (2017). Repeated E-book Reading and Its Contribution to Learning New Words among Kindergartners. Journal of Education and Training Studies, 5(7),60-72.

1 Saadi, K., Lane-Kelso, M., Al Hafeedh, A., Al Sheithani, Z., \& Al Wishahi, M. (2017). Are We Ready for E-Books? Omani University Students' Uses and Perceptions of EBooks. Turkish Online Journal of Educational Technology, 16(2),11-25.

Lai, C.-S. (2016). Integrating E-Books into Science Teaching by Preservice Elementary School Teachers. Journal of Education in Science, Environment and Health, 2(1),57-66.

Lebert, M. (2009). A Short History of eBooks. Toronto: University of Toronto.

Pabrua Batoon, M. V., Glasserman Morales, L. D., \& Yanez Figueroa, J. A. (2018). Instructional Design to Measure the Efficacy of Interactive E-Books in a High School Setting. Turkish Online Journal of Distance Education, 19(2),47-60.

Paivio, A. (2006). Dual Coding Theory and Education. Ontario: University of Western Ontario. 
Plangsorn, B., \& Poopan, S. (2017). Development of producing and using e-books competencies of teachers in Chachengsao, Thailand. World Journal on Educational Technology, 9(2),112-117.

Prayekti. (2018). The Influence of Cognitive Learning Style and Learning Independence on the Students' Learning Outcomes. Higher Education Studies, 8(2),37-46.

Samia, D., \& Amirat, A. (2017). Adaptation with Four Dimensional Personalization Criteria Based on Felder Silverman Model. International Journal of Distance Education Technologies, 15(4),1-20.

Sellah, L., Jacinta, K., \& Helen, M. (2017). Analysis of Student-Teacher Cognitive Styles Interaction: An Approach to Understanding Learner Performance. Journal of Education and Practice, 8(14),10-20.

Šmajdek, A., \& Selan, J. (2016). The Impact of Active Visualisation of High School Students on the Ability to Memorise Verbal Definitions. Center for Educational Policy Studies Journal, 6(4),163-186.

Usta, N. D., \& Güntepe, E. T. (2017). Pre-Service Teachers' Material Development Process Based on the ADDIE Model: E-Book Design. Journal of Education and Training Studies, 5(12),199-210.

Wang, P.-Y., \& Huang, C.-K. (2015). The Effect of Visual Cueing and Control Design on Children's Reading Achievement of Audio E-Books with Tablet Computers. Journal of Curriculum and Teaching, 4(1),96-107.

Yagcioglu, O. (2016). The Positive Effects of Cognitive Learning Styles in ELT Classes. European Journal of English Language Teaching, 1(2),78-91.

Zsofia K., T., Elise K, S., \& Adriana G, B. (2015). Benefits and Pitfalls of Multimedia and Interactive Features in Technology-Enhanced Storybooks: A Meta-Analysis. Review of Educational Research, 84(4),698-739. 

be applied to their work. Under the terms of this license, no permission is required from the author(s) or publisher for members of the community to copy, distribute, transmit or adapt the article content, providing a proper, prominent and unambiguous attribution to the authors in a manner that makes clear that the materials are being reused under permission of a Creative Commons License. Views, opinions and conclusions expressed in this research article are views, opinions and conclusions of the author(s). Open Access Publishing Group and European Journal of Open Education andE-learning Studies shall not be responsible or answerable for any loss, damage or liability caused in relation to/arising out of conflict of interests, copyright violations and inappropriate or inaccurate use of any kind content related or integrated on the research work. All the published works are meeting the Open Access Publishing requirements and can be freely accessed, shared, modified, distributed and used in educational, commercial and non-commercial purposes under a Creative Commons Attribution 4.0 International License (CC BY 4.0). 